\title{
Portable, digital telethermocamera for monitoring total hip and knee replacement surgical site healing and the occurrence of septic complications.
}

\author{
by C.L. Romanò, G. Manzi, M. Calamita, N. Logoluso
}

Dept. of Chirurgia Ricostruttiva e delle Infezioni Osteo-articolari, Istituto Ortopedico I.R.C.C.S. Galeazzi,via R. Galeazzi, 4 - 20161 Milano, Italy, carlo.romano@grupposandonato.it

\section{Abstract}

With more than one million implants performed each year in Europe, joint replacement is one of the most successful surgical intervention. However, septic complications remain one of the first reasons for implant failure, often posing difficult diagnostic dilemmas. We present the normal reference thermographic values of wound healing after total knee and hip replacements and report on the results of a prospective study focused on the diagnostic value of telethermography to differentiate septic versus aseptic painful knee prosthesis. Portable, digital telethermocameras are reliable, easy-to-use and relatively low-cost and their large scale use in the routine clinical setting should be considered.

\section{Introduction}

Total hip and knee replacements are among the most performed and successful interventions in orthopaedics, with more than $\mathbf{1 5 0 . 0 0 0 ~ n e w ~ p r o s t h e s i s ~ i m p l a n t e d ~ e a c h ~ y e a r ~ i n ~ I t a l y ~ a n d ~ m o r e ~ t h a n ~ o n e ~ m i l l i o n ~ i n ~ E u r o p e ; ~ h o w e v e r , ~ w i t h ~}$ an incidence ranging from $0.5 \%$ to $5 \%$, wound healing complications and surgical site infections remain difficult to diagnose and challenging to treat, with extremely high social and economical associated costs.

Isolated reports showed the efficacy of infra-red thermography in monitoring wound healing and septic complications, however no long term analysis has ever been performed and no data are available as to concern the telethermographic pattern of the surgical site healing after total hip and knee prosthesis and no study has investigated the diagnostic value of this technology to assess late septic complications after joint replacement.

\section{Material and methods}

In this prospective, observational, non-randomized cohort study, two groups of 60 and 40 consecutive patients, undergoing respectively total hip or knee replacement were examined at fixed intervals of time from the day before surgery to one year after the intervention, using a portable digital telethermocamera (NEC F30, Fig. 1). The results were compared with the contralateral side and with laboratory data.

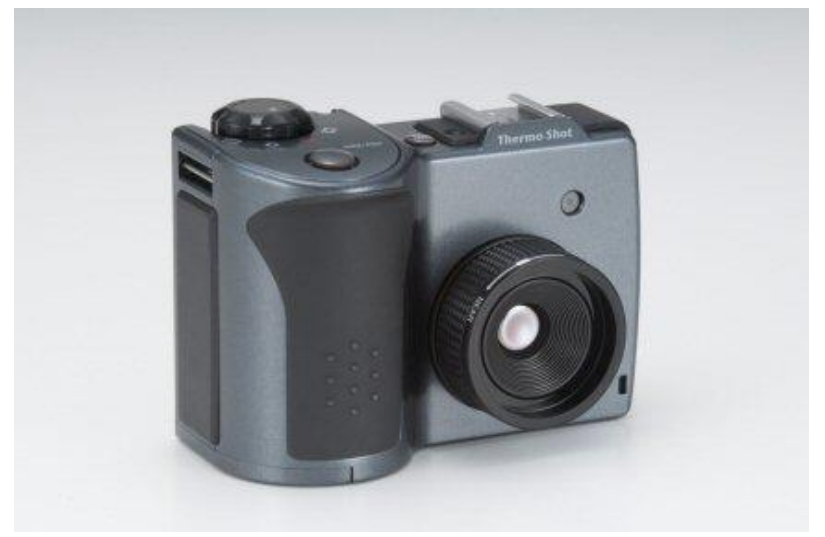

Fig. 1. The NEC-F 30 is a lightweight (350 grams), portable digital telethermocamera, particularly suitable for medical applications. Measuring range: -20 to $100^{\circ} \mathrm{C}$, resolution: $0.1^{\circ} \mathrm{C}$ at $30^{\circ} \mathrm{C}$.

A further analysis was then undertaken on another group of 70 patients, suffering for painful total knee arthroplasty (TKA) after a minimum of ten months after surgery, to differentiate between septic $(\mathrm{N}=36)$ and aseptic $(\mathrm{N}=34)$ painful prosthesis. Patients suffering from known rheumatic or chronic inflammatory joint disease were excluded from the study. Statistical analysis was performed with the unpaired Student's t test. 


\section{Results}

\subsection{Uncomplicated healing of the surgical site after total knee or hip arthroplasty}

No thermographic difference was observed pre-operatively between the affected and the contralateral side in both groups. After the intervention, a steep increase in the temperature of the operated joint has been recorded both after total hip and knee replacement, with a peak mean differential temperature between the operated and non-operated joint of $3.1 \pm 0.8^{\circ} \mathrm{C}$ after total hip replacement and of $3.4 \pm 0.7{ }^{\circ} \mathrm{C}$ after total knee replacement, three days postoperatively. Thereafter mean differential temperature slowly declined to $0.7 \pm 1.1{ }^{\circ} \mathrm{C}$ and to $0.5 \pm 1.3{ }^{\circ} \mathrm{C}$ at 60 days and to $0.0 \pm 1.0^{\circ} \mathrm{C}$ and $-0.1 \pm 1.1{ }^{\circ} \mathrm{C} 90$ days post-operatively, respectively. No further changes were observed for up to one year after surgery. Results were similar when considering the average differential temperature of an the elliptical area with the main axis driven on the surgical wound (Surgical Site Area, SSA), or when considering the differential temperature of the Hottest Spot (HS) retrieved within the same elliptical area.

\subsection{Differential diagnosis of painful total knee arthroplasty}

The absolute recorded temperature in painful knee arthroplasty (TKA) with septic complication is reported in Table 1, where an average differential temperature of the affected versus not affected knee of $1.9^{\circ} \mathrm{C}$ can be observed in septic complications, compared to $0.3{ }^{\circ} \mathrm{C}$ in aseptic prosthetic loosening. The difference is extremely statistically significant.

Table 1. Thermographic average values in aseptic and septic painful total knee arthroplasty (TKA)

\begin{tabular}{|l|c|c|c|}
\hline & $\begin{array}{l}\text { Aseptic painful TKA } \\
(\mathbf{N = 3 4 )}\end{array}$ & $\begin{array}{l}\text { Septic painful TKA } \\
(\mathbf{N = 3 6 )}\end{array}$ & P \\
\hline Hottest Spot, HS & $37.3 \pm 1.5^{\circ} \mathrm{C}$ & $38.8 \pm 1.7^{\circ} \mathrm{C}$ & \\
\hline Surgical Site Area, SSA & $35.7 \pm 1.6^{\circ} \mathrm{C}$ & $37.3 \pm 1.8^{\circ} \mathrm{C}$ & \\
\hline $\begin{array}{l}\text { Hottest Spot (differential temperature: } \\
\text { affected minus not affected knee) }\end{array}$ & $0.3 \pm 0.7^{\circ} \mathrm{C}$ & $1.9 \pm 1.2^{\circ} \mathrm{C}$ & $<0.0001$ \\
\hline $\begin{array}{l}\text { Surgical Site Area } \\
\text { (differential temperature) }\end{array}$ & $0.6 \pm 0.5^{\circ} \mathrm{C}$ & $2.2 \pm 1.5^{\circ} \mathrm{C}$ & $<0.0001$ \\
\hline
\end{tabular}

Considering as normal reference value (no infection) a differential temperature between the affected and not affected knee equal or less than $1.0^{\circ} \mathrm{C}$ (values higher than $1.0^{\circ} \mathrm{C}$ are considered positive for peri-prosthetic infection), telethermographic analysis showed, in this series of patients, a sensitivity of $89 \%$ and a specificity of $91 \%$ in differentiating septic (Fig. 2) versus aseptic (Fig. 3) painful total knee prosthesis, examined at a minimum of ten months from prosthetic implant (cf. Table 2).
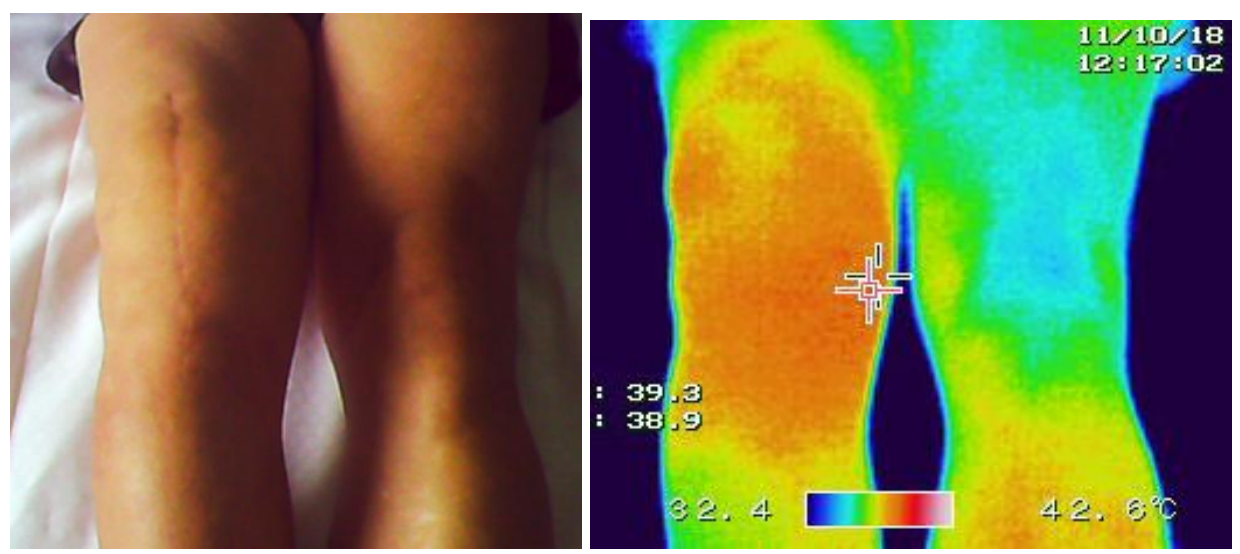

Fig. 2. Septic right painful total knee arthroplasty. Mean differential temperature (Hottest Spot): $2.8^{\circ} \mathrm{C}$. 


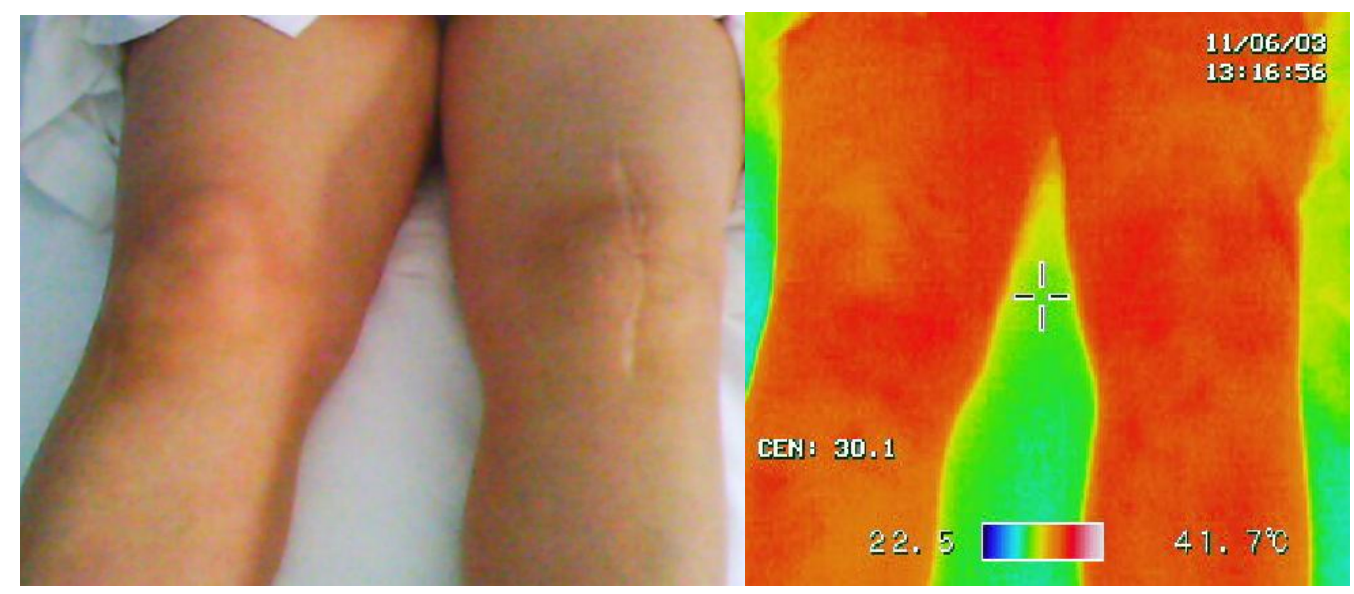

Fig. 3. Aseptic left painful total knee arthroplasty. Mean differential temperature (Hottest Spot): $0.3^{\circ} \mathrm{C}$.

Table 2. Value of telethermography in diagnosing peri-prosthetic late infection after total knee arthroplasty

\begin{tabular}{|l|c|c|c|}
\hline & & \multicolumn{2}{|c|}{ 95\% Confidence Interval } \\
\hline & Estimated & & Upper Limit \\
\cline { 3 - 4 } & Value & Lower Limit & 0.96 \\
\hline Sensitivity & 0.89 & 0.73 & 0.98 \\
\hline Specificity & 0.91 & 0.74 & \\
\hline Predictive Value & & & 0.97 \\
\hline Positive & 0.91 & 0.78 & 0.95 \\
\hline
\end{tabular}

\section{Discussion}

Telethermography through a portable digital camera appears a reliable, not invasive, not irradiating, easy-to-use and low-cost tool to monitor surgical site following hip or knee arthroplasty [1,2]. and to differentiate aseptic painful knee prosthesis versus late peri-prosthetic septic complications. Dedicated software and user's friendly, portable, digital telethermocameras do open a huge potential range of application of this imaging technique in the medico-surgical field.

\section{REFERENCES}

[1] Romanò C.L., Romanò CL, Logoluso N, Dell'oro F, Elia A, Drago L. (2011) Telethermographic findings after uncomplicated and septic total knee replacement. Knee. 2011 Mar 25. [Epub ahead of print] PMID: 21441031.

[2] Romanò C.L., Romanò D., Logoluso N., Meani E. (2011) Surgical site healing after total hip and knee replacements shows a similar telethermographic pattern. J Orthop Traumatol. 12(2):81-6. 